\title{
COMPARATIVE STUDY AND IMPLEMENTATION OF INCREMENTAL CONDUCTANCE METHOD AND PERTURB AND OBSERVE METHOD WITH BUCK CONVERTER BY USING ARDUINO
}

\author{
Roshan Kini ${ }^{1}$, Geetha.Narayanan ${ }^{2}$, Aditya Dalvi ${ }^{3}$ \\ ${ }^{1}$ PG. Student, Electronics and telecomunication Department, Vidyalankar Institute of Technology, Maharashtra,India \\ ${ }_{2}$ Associate Professor,Electronics Department, Vidyalankar Institute of Technology,Maharashtra,India \\ ${ }^{3} \underline{U}$ G. Student, Information Technology, Mumbai University, Maharashtra, India
}

\begin{abstract}
Maximum Power Point techniques (MPPT) of Photovoltaic array are used to continuously deliver highest possible power to the load when variation in solar irradiation and temperature occur. This is achieved by many algorithms such as perturbs and observer method, incremental conductance method, constant voltage method, fuzzy logic method, neural network etc. A DC/DC converter (boost, buck, Cuk) serves the purpose of transferring maximum power from the solar PV module to the load. In this project we compared perturb and observe method and incremental conductance method with DC-DC Buck converter by implementing hardware using Arduino Duemilanove as a prototype board.
\end{abstract}

Key Words: MPPT, buck converter, solar voltage and current sensing, Incremental conductance method (INC), Perturb and Observe method, Matlab real time graph, and Arduino Duemilanove, Lead acid battery.

\section{INTRODUCTION}

Renewable energy is different from non-renewable energy because renewable energy never runs out. It will never run out because it comes from the wind, the sun, the ocean waves, flowing rivers, and the heat that is deep inside the earth. There will always be wind and sun, rivers and waves, and the earth's heat, so we will always be able to get energy from them. Renewable energy also is more special because it does not hurt the environment [22].

Solar energy i.e. energy from the sun provide consistent and steady source of solar power throughout the year. As our natural resources set to decline in the years to come, it's important for the whole world to move towards renewable sources. The main benefit of solar energy that it can be easily deployed by both home and business users as it does not require any huge set up like in case of wind and geothermal power stations. Solar energy not only benefits individual owners, but also benefit environment as well. Solar energy is non-polluting, clean, reliable and renewable source of electricity. It does not pollute the air by releasing harmful gases like carbon dioxide, nitrogen oxide and sulphur oxide [20], [21].

\section{MPPT METHODS}

All MPPT methods follow the same Goal which is maximizing the PV array output power by tracking the maximum power on every operating condition as shown in Fig -2.
A DC/DC converter (Boost, Buck, Cuck) serves the purpose of transferring maximum power from the solar PV module to the load. According to Maximum Power Transfer theorem, it state that maximum power delivered from source to a load when the load resistance is equal to the source resistance. Thus, DC/DC converter is introduced between the solar PV module and the load as Shown in Fig -1. By changing the duty cycle (D), the load impedance as seen by the source is varied and matched at the point of the peak power with the source so as to transfer the maximum power. The MPPT algorithm varies the duty cycle of a DC/DC converter that ensures the output voltage of a $\mathrm{PV}$ panel follow a reference voltage at any solar irradiance, temperature and load conditions [2].

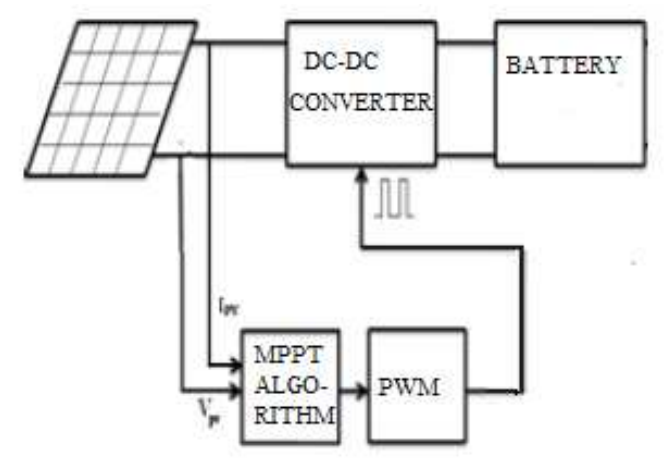

Fig -1: Block diagram of MPPT [20]. 


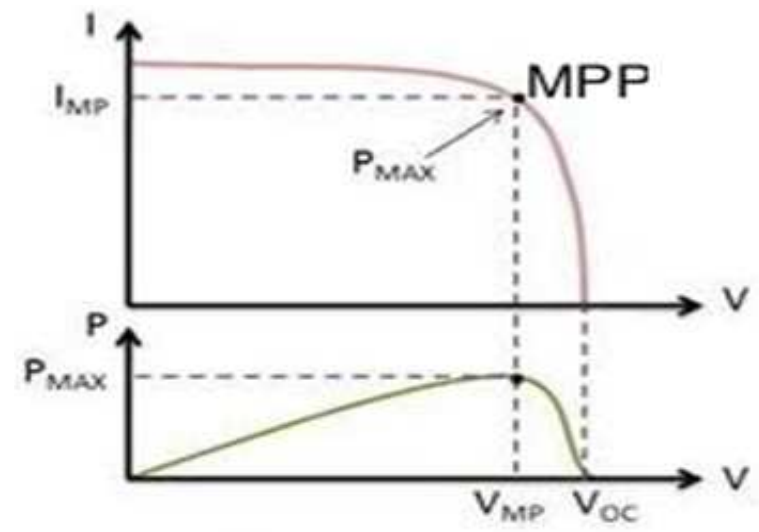

Fig -2: I-V and P-V characteristics of solar panel.

There are many algorithms are present which are able to track Maximum Power Point (MPP). Some of them are simple, such as those based on voltage and current feedback, some are more complicated, such as Neural Network (NN) and Fuzzy Logic (FLC) and some MPPT method has medium complexity such as perturb and observe method $(\mathrm{P} \& \mathrm{O})$ or the incremental conductance method (INC). These methods also vary in complexity, sensor requirement, speed of convergence, cost, range of operation, popularity, ability to detect multiple local maxima, and their applications [4] [17].

$\mathrm{P} \& \mathrm{O}$ and INC algorithms are in the center of consideration because of their simplicity and ease of implementation.

\subsection{Perturb \& Observe Method. (P\&O)}

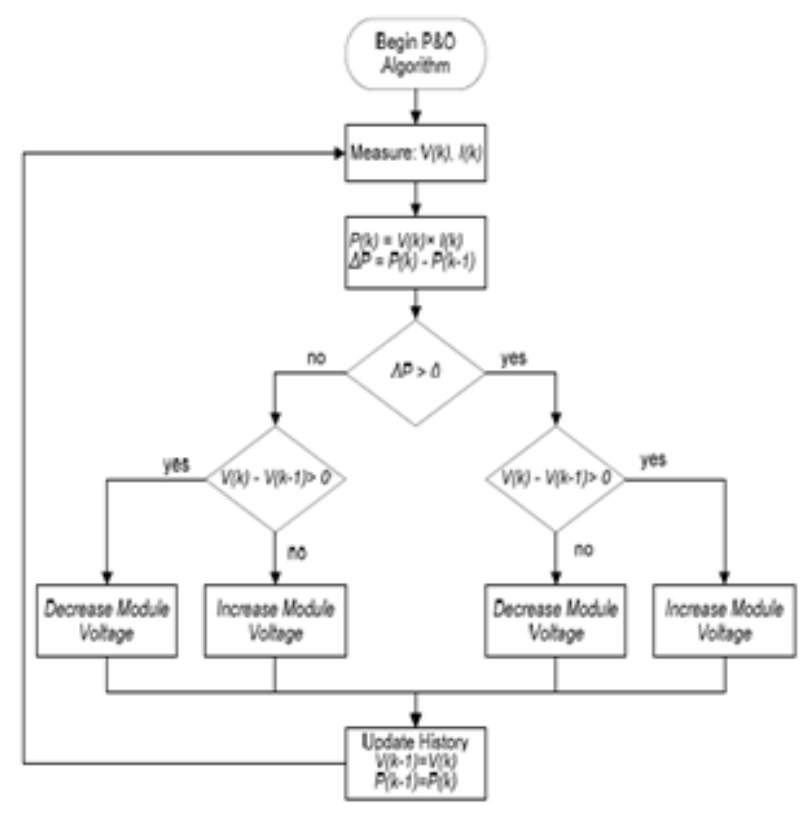

Fig -3: Flow chart of perturb and observe method [1].

Perturb \& Observe $(\mathrm{P} \& \mathrm{O})$ is the simplest method. In this we use two sensor, that is the voltage sensor and current sensor to sense the PV array voltage and current so the cost of implementation is less and hence easy to implement. The time complexity of this algorithm is very less but on reaching very close to the MPP it doesn't stop at the MPP and keeps on perturbing on both the directions. When this happens the algorithm has reached very close to the MPP and we can set an appropriate error limit or can use a wait function which ends up increasing the time complexity of the algorithm [5], [6].

The $\mathrm{P} \& \mathrm{O}$ algorithms operate by periodically perturbing (i.e. Incrementing or decrementing) the array terminal voltage or current and comparing the PV output power with that of the previous perturbation cycle.

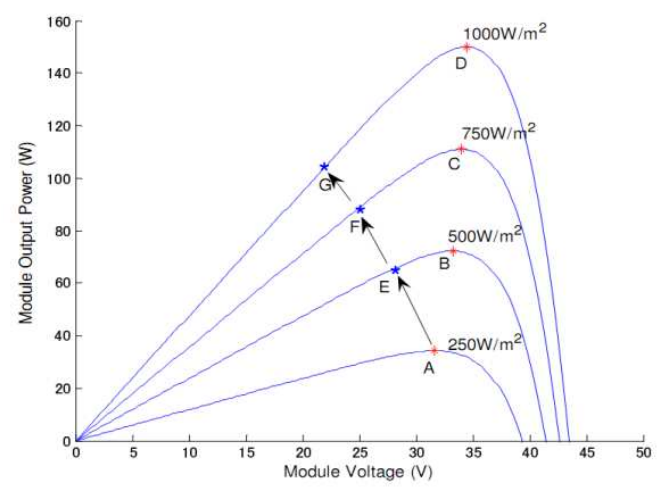

Fig -4: Tracking wrong MPP by perturb and observe method.

However the method does not take account of the rapid change of irradiation level (due to which MPPT changes) and considers it as a change in MPP due to perturbation and ends up calculating the wrong MPP as shown in fig -4. To avoid this problem we can use the incremental conductance method [2].

\subsection{Incremental Conductance Method. (INC)}

The incremental conductance method is based on the fact that the slope of the PV array power curve is zero at the MPP, positive on the left of the MPP, and negative on the right, as given by [17].

$\frac{d P}{d V}=0$, at MPP
$\frac{d P}{d V}=>0$, left of MPP
$\frac{d P}{d V}=<0$, Right of MPP
$\frac{d P}{d V}=\frac{d(I V)}{d V}=I+V \frac{d(I)}{d V} \frac{d(I)}{d V}$

From (1) and (2), we get.

$\frac{\mathrm{d}(\mathrm{I})}{\mathrm{dV}}+\mathrm{I} / \mathrm{V}=0$, at MPP
$\frac{\mathrm{d}(\mathrm{I})}{\mathrm{dV}}+\mathrm{I} / \mathrm{V}>0$, Left of MPP
$\frac{\mathrm{d}(\mathrm{I})}{\mathrm{dV}}+\mathrm{I} / \mathrm{V}<0$, Right of MPP

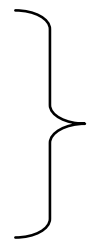


The MPP can thus be tracked by comparing the instantaneous conductance $(\mathrm{I} / \mathrm{V})$ to the incremental conductance (I/V) as shown in the flow chart in Fig -5 .

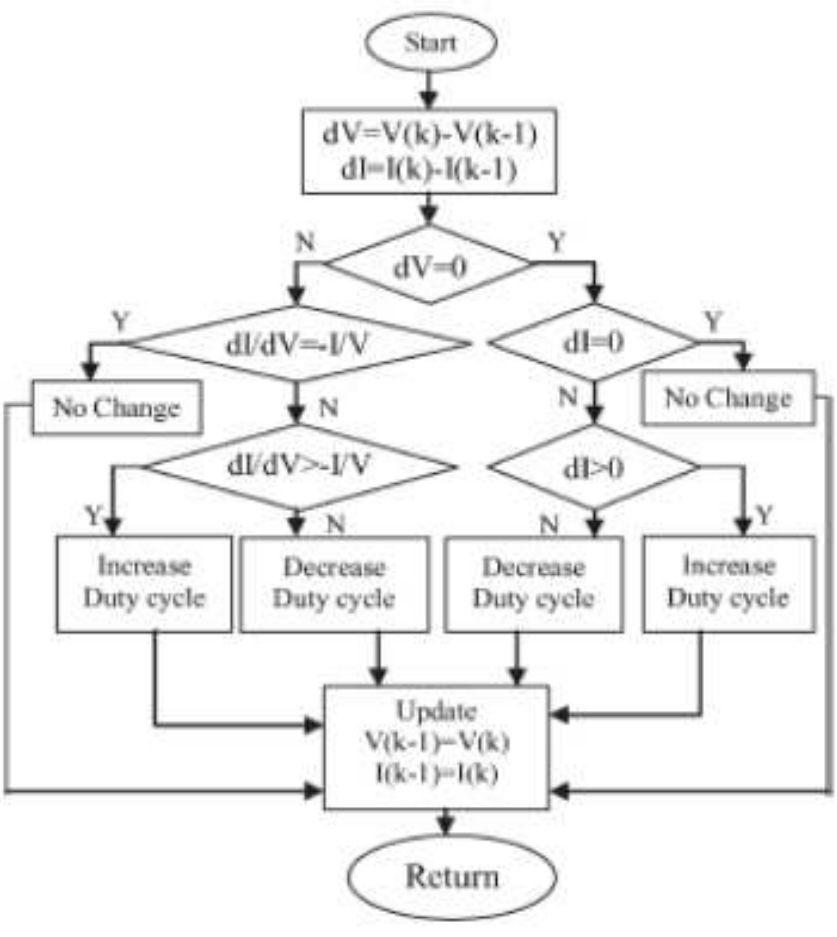

Fig -5: Flow chart of incremental conductance method [3].

The incremental conductance method also uses voltage and current sensors to sense the output voltage and current of the PV array. The left hand side is the instantaneous conductance of the solar panel. When this instantaneous conductance equals the conductance of the solar then MPP is reached [19], [3].

\section{SYSTEM DESCRIPTIONS}

To Charge $12 \mathrm{~V}$ lead acid battery by using solar panel incorporating MPPT algorithm in Charger (DC-DC Converter). We have to consider following parameters.

\subsection{Solar panel or photovoltaic module.}

A photovoltaic module is a packaged, connected assembly of solar cells. A single solar module can produce only a limited amount of power; most installations contain multiple modules, but in this project connected two solar module parallel. (All Electrical Parameters specified at STC: $25^{\circ} \mathrm{C}$ cell temperature; $100 \mathrm{~m} \mathrm{~W} / \mathrm{cm}^{2}$ irradiance ;)

Specifications of 1st solar panel:

Product Code: SPI1275

Max Power: 40W $\pm 5 \%$

Max Power Voltage: 17V

Max Power Current: 2.26A

Open Circuit Voltage: 21V

Short Circuit Current: 2.49A

Weight: $6.8 \mathrm{Kgs}$
Specifications of 2nd solar panel:

Product Code: SPI1220

Max Power: $10 \mathrm{~W} \pm 5 \%$

Max Power Voltage: 17V

Max Power Current: 0.61A

Open Circuit Voltage: 21V

Short Circuit Current: 0.61A

Weight: $1.8 \mathrm{Kgs}$

\subsection{Microcontroller(Arduino ATmega 328 p)}

Arduino Duemilanove is a single-board microcontroller, consisting of an Atmel ATmega 328p along with various other components that allow for easy programming and access to various digital and analog input/output pins. The ATmega 328p microcontroller is preloaded with the Arduino boot loader, allowing this chip to be programmed in the Arduino programming language.

The Arduino Duemilanove can be powered via the USB connection or with an external power supply. External (nonUSB) power can come either from an AC-to-DC adapter (wall-wart) or battery. The board can operate on an external supply of 6 to 20 volts. If supplied with less than $7 \mathrm{~V}$, however, the $5 \mathrm{~V}$ pin may have less than $5 \mathrm{~V}$ and the board may be unstable. If supply is more than $12 \mathrm{~V}$, the voltage regulator may overheat and damage the board. The recommended range is 7 to 12 volts [10]. Therefore In this project since the open circuit voltage of solar panel is $21 \mathrm{~V}$ which is higher than the recommended voltage of Arduino a voltage regulator IC7809 is used between solar panel and $V_{\text {IN }}$ pin of Arduino.

\subsection{Solar \& Battery Voltage sensor.}

In this project we have to constantly monitor the battery and solar voltage. Unfortunately, sensor can only measure voltages up to $5 \mathrm{~V}$. So a voltage divider circuit as shown in Fig .4 is connected to reduce the voltage across analog input pin of Arduino to measurable limit.

The values of resistance (R1 \& R2) of a voltage divider circuit are selected such that the output voltage across R2 (V2) is not more than 5V. Resistance for voltage divider circuit is selected as $R 1=10 \mathrm{~K}$ and $\mathrm{R} 2=2.2 \mathrm{~K}$. The solar open circuit voltage is $21 \mathrm{~V}$ (which is maximum solar voltage) therefore maximum voltage across $\mathrm{R} 2$ is $3.8 \mathrm{~V}$ which is acceptable for voltage sensing circuit as shown in Fig -6 . Before feeding this analog voltage into the Arduino, it needed to go through some filtering to maintain an accurate reading. V2 was first fed into a filtering capacitor $(\mathrm{C} 1=0.1$ $\mu \mathrm{f}$ ) in order to smooth the output voltage and prevent noise spikes in the signal which can result false readings. The signal after filtering is fed to the Analog pin in the microcontroller .It is later used to implement the Maximum Power Point (MPP) algorithm [15], [18].

The Arduino AVR chip has 10 bit A to D resolution, Therefore the AnalogRead () function is used to measure the voltage as an integer between 0 and 1023. One integer's value is equal to $0.00488 \mathrm{~V}(5 \mathrm{~V} / 1024)$. The exact voltage across solar panel can be calculated as 
Sol. volts $=((\mathrm{R} 1+\mathrm{R} 2) / \mathrm{R} 2) * 0.00488 *$ solar Analog input [8], [9].
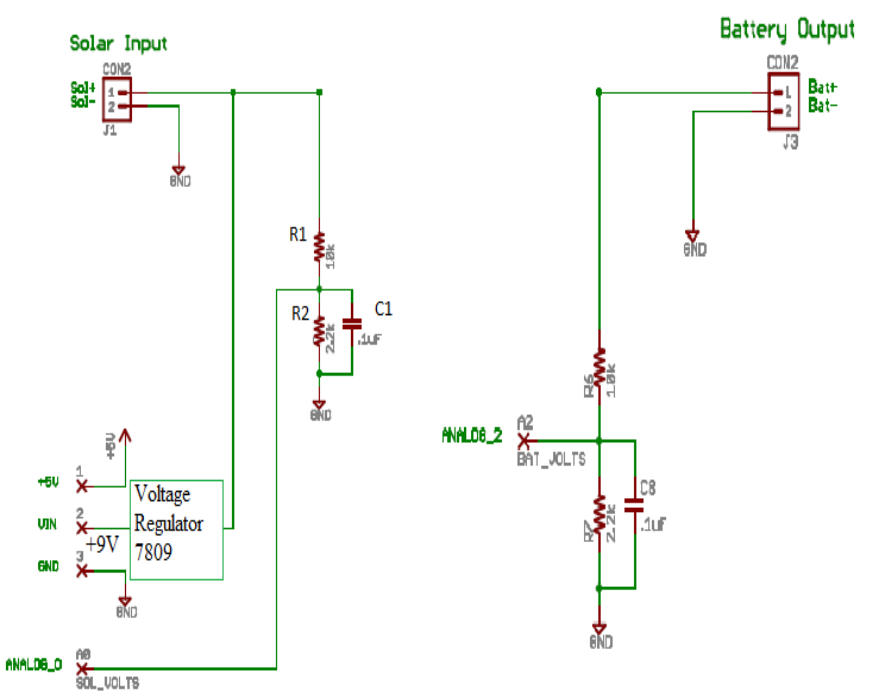

Fig -6: Solar and battery voltage sensor.

\subsection{Solar Current sensor}

The current sensor played a significant role in the realization of the MPPT in order to achieve the maximum output power from the panel. I have used MAX4173H for the design since it was used in Tim Nolan MPPT project which I referred for this project. Information and description about MAX4173 is provided in [14].

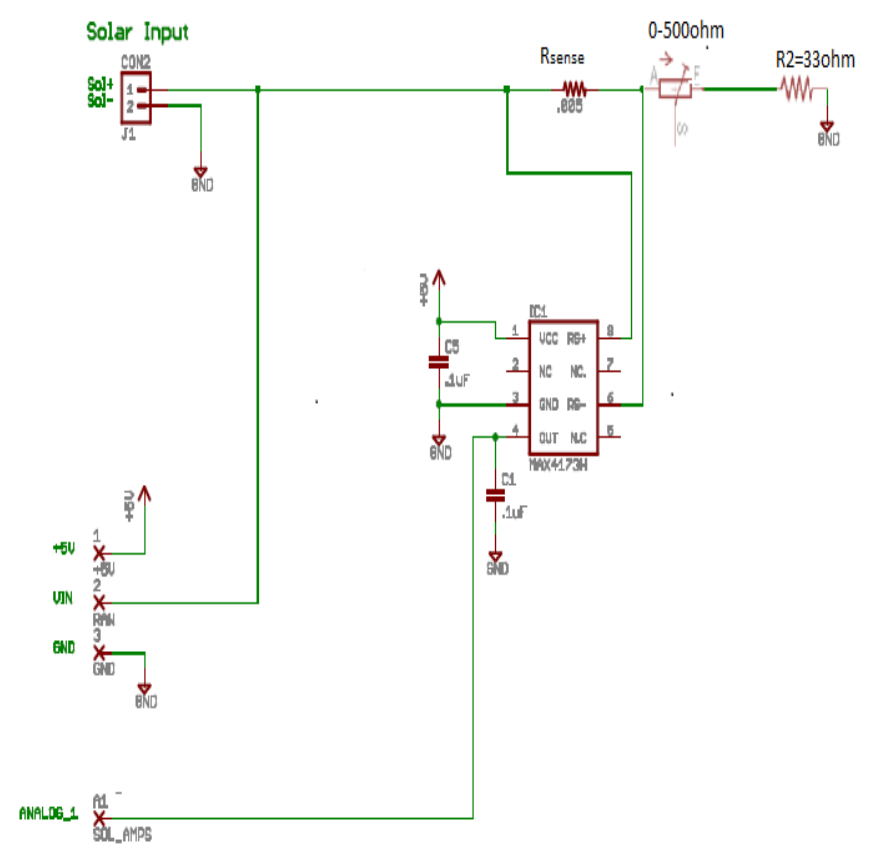

Fig -7: Circuit diagram of solar current sensor.

Current from the source flows through RSENSE to the load as shown in Fig -7. So, $\mathrm{V}_{\text {OUT }}=($ GAIN $)\left(\mathrm{R}_{\mathrm{SENSE}}\right)\left(\mathrm{I}_{\mathrm{LOAD}}\right)[22]$
Where, GAIN $=100$ for $\mathrm{MAX} 4173 \mathrm{H}$ and $\mathrm{R}_{\mathrm{SENSE}}=0.005 \Omega$, Therefore, $\mathrm{V}_{\text {OUT }}=(100)(0.005)\left(\mathrm{I}_{\mathrm{LOAD}}\right)=(0.5)\left(\mathrm{I}_{\mathrm{LOAD}}\right)[8]$.

\subsection{MPPT charger (DC-DC Convertor)}

Some analysis and design of buck converter are provided in [9], [15] and a comparative study on different schemes of switching converters is presented in the literature [33].

The components for the buck converter used in project were selected as follows:

Input inductor $\mathrm{L} 1=33 \mu \mathrm{H}$;

Input Capacitor $\mathrm{C} 1=35 \mathrm{~V}, 100$ uf Aluminum Electrolytic

Capacitors Switching

MOSFET $=$ IRFZ44N

Diode $=$ Schottky rectifier diode: A 1 N5822

Output Capacitor C2 $=18 \mathrm{~V}, 220$ uf Aluminum Electrolyte

Capacitor

Resistive load $=$ Lead acid battery

Switching frequency $=50 \mathrm{kHz}$;

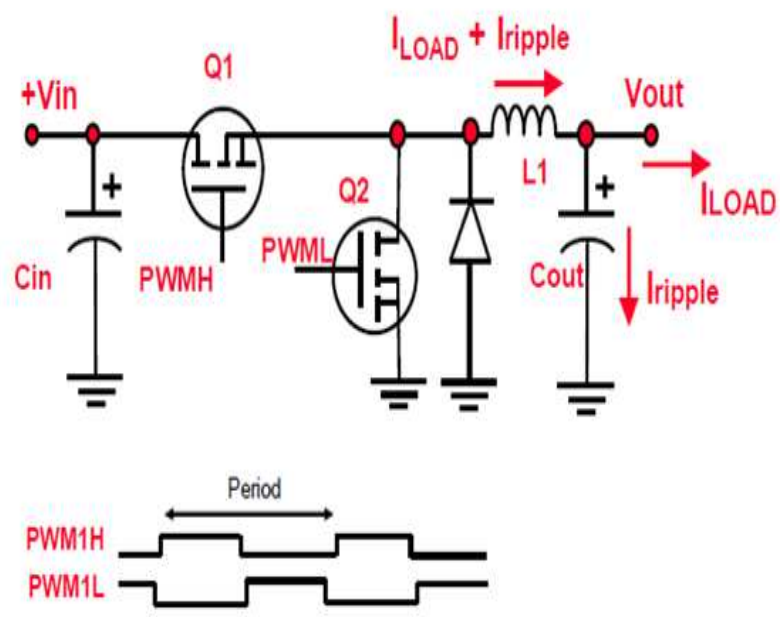

Fig -8: Circuit synchronous buck converter [39].

Q1 is the main switching MOSFET for the buck converter and Q2 is the synchronous switching MOSFET as shown in Fig -8. The MOSFET are driven by IC2 which is an IR2104 MOSFET driver. The IR2104 takes the PWM signal from the controller input on pin 2 and uses it to drive the switching MOSFETs. The IR2104 can also be shut down with the control from the processor on pin 3. Information and description about IR2104 is provided in [13].

I connected diode between battery and DC to DC Converter which eliminate the risk of current reversal from the battery during night time, in case the battery is directly connected to the panel.

\subsection{Battery charging algorithm (Lead-Acid Battery).}

Since solar cells can only generate power at certain times of the day, a storage element is required in all solar power systems. The most common form of the energy storage for the stand alone solar power system is battery technology. The basic functions of the battery management are to control 
the charge/discharge of the battery, to protect the battery from damage, to prolong the life of the battery, and to maintain the battery in a state to fulfill the functional requirements. Battery management systems for a solar power system with lead acid battery are discussed in [11], [12].

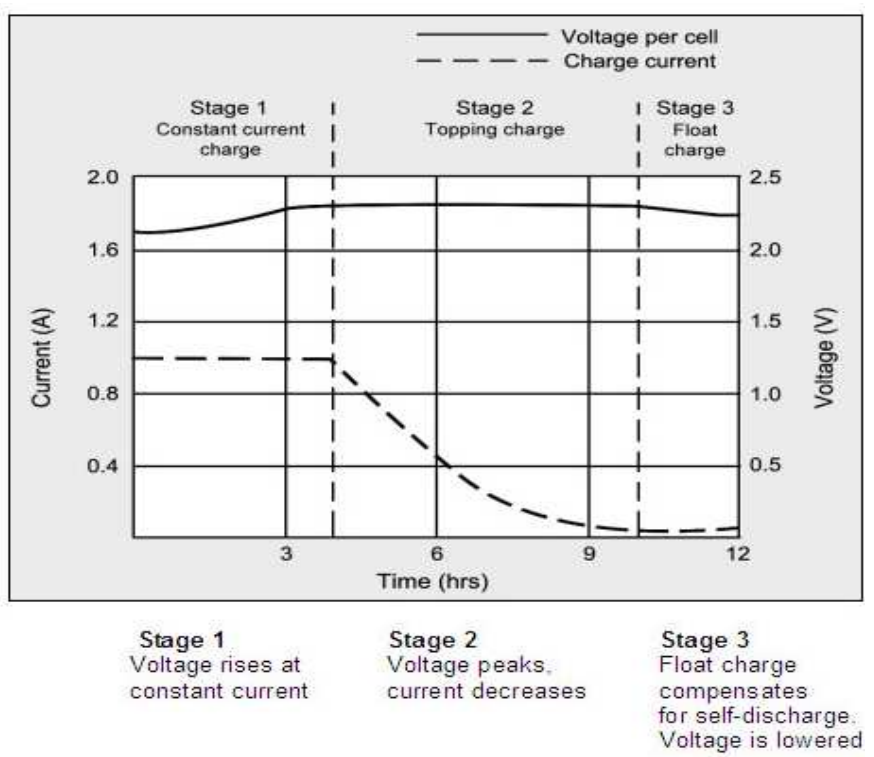

Fig -9: Charging diagram for a typical lead-acid battery[11].

Battery Specifications:

Product code: CP12170

Chemistry: Sealed Lead Acid

Voltage: $12 \mathrm{~V}$

Nominal Capacity: 18Ah

Weight (lbs): 12.6

Cycle Use: $14.5-14.9 \mathrm{~V}$

Standby Use: $13.6-13.8 \mathrm{~V}$

Initial Current: Less than 7.2A

I also added the battery management algorithm in my MPPT project to keep the batteries from overcharging. This algorithm has four states on, off, bulk and float. Hence the maximum power point tracker can be in one of the following four states:

Off State: When there is little or no power coming from the solar panel, the device should go into an off state to protect the battery from leaking back into the solar panel.

On State: When there is minimal power coming from the solar panel, enough to power the system but not enough to move to the next state, the system turns on and attempts to deliver all of the power.

Bulk State: This is the main charging state where the MPPT algorithms were most relevant. Here the maximum power point was determined and the battery was charged accordingly.
Float State: Once the battery reached a high enough voltage and was close to fully charged, the controller then moved into the float state. In this state, the goal was to maintain the voltage level and compensate for self-discharge [7, 12].

\subsection{Matlab interface with Arduino for serial communication}

MATLAB Support Package for Arduino (also referred to as "Arduino-I/O Package") allows us to communicate with an Arduino over a serial port. It consists of a MATLAB API on the host computer and a server program that runs on the Arduino. Together, they allow us to access transmit and receive serial data from Arduino.

In this project we received data from Arduino such as solar current reading $(\mathrm{I})$, solar voltage reading $(\mathrm{V})$, solar power reading $(\mathrm{P})$, time (in $\mathrm{Sec})(\mathrm{T})$, battery voltage reading $(\mathrm{Vb})$ and develop a real time plot of I-V, P-V on Matlab to monitor maximum power point of solar array And also plot graph of $\mathrm{V}, \mathrm{P}, \mathrm{I}, \mathrm{Vb}$ with respect to time to check variation in this parameter.

\section{TESTING AND RESULT.}

\subsection{Software Testing}

The MPPT software and the algorithms that it encompasses were tested using the test plan explained in Table 2.

Table -1: Software testing plan.

\begin{tabular}{|c|c|c|c|}
\hline Step & Procedure & Expected Results & $\begin{array}{l}\text { Actual } \\
\text { Results } \\
\text { Status }\end{array}$ \\
\hline 1 & $\begin{array}{l}\text { Hard-code values } \\
\text { for current and } \\
\text { voltage }\end{array}$ & $\begin{array}{l}\text { Should calculate the } \\
\text { correct value for } \\
\text { power }\end{array}$ & Complete \\
\hline 2 & $\begin{array}{l}\text { Write a data to } \\
\text { print to the screen }\end{array}$ & 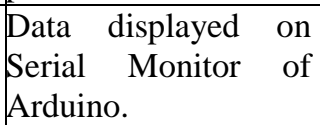 & Complete \\
\hline 3 & $\begin{array}{l}\text { Hard-code values } \\
\text { for different } \\
\text { charging states }\end{array}$ & $\begin{array}{l}\text { Algorithm will } \\
\text { change into different } \\
\text { states based on the } \\
\text { current and voltage }\end{array}$ & Complete \\
\hline 4 & $\begin{array}{l}\text { Take real } \\
\text { reading of bothe } \\
\text { algorithms (P\&O } \\
\text { and INC) } \\
\text { Matlab for } 100 \\
\text { second and plot } \\
\text { graph of I vs. V, P } \\
\text { vs. V and also plot } \\
\text { graph of P, V, I, } \\
\text { Vb with respect to } \\
\text { time. }\end{array}$ & $\begin{array}{l}\text { Results of (P\&O) and } \\
\text { INC method display } \\
\text { in Fig.10 to Fig. } 15 .\end{array}$ & Complete \\
\hline 5 & $\begin{array}{l}\text { Compare } \\
\text { method (P\&O and } \\
\text { INC) based } \\
\text { result. }\end{array}$ & $\begin{array}{l}\text { Result of comparison } \\
\text { of both method } \\
\text { display from Fig. } 35 \\
\text { to Fig.38 }\end{array}$ & Complete \\
\hline
\end{tabular}




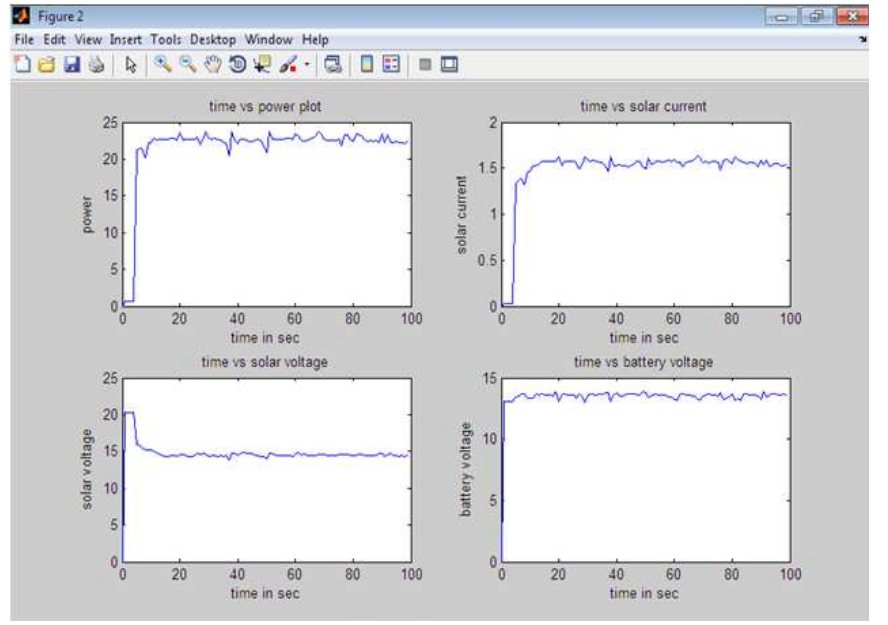

Fig -10: Graph of solar power, current, voltage and battery voltage with respect to time ( $\mathrm{P} \& \mathrm{O})$,

Date: 26/12/2013, Time: 2:45

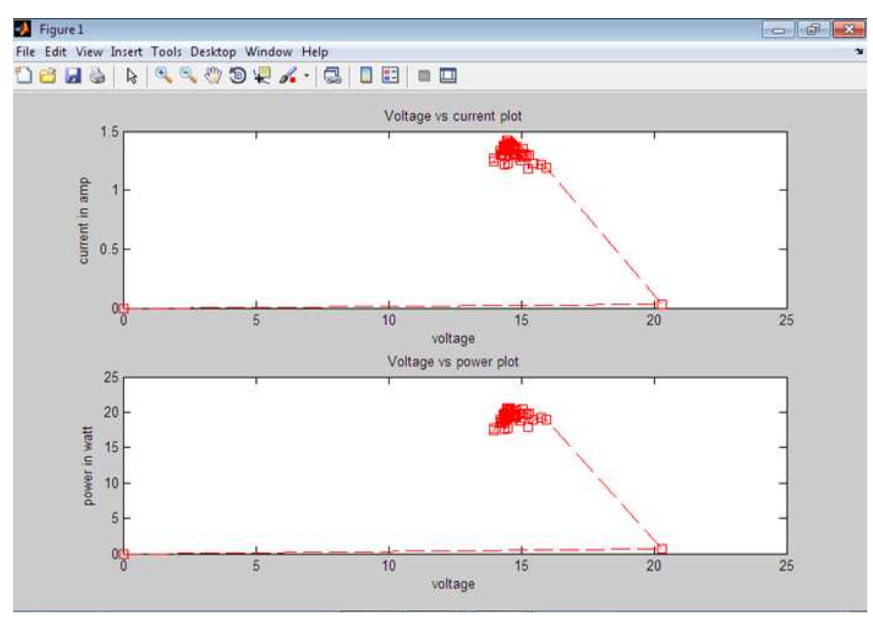

Fig -11: Graph of solar current vs. solar voltage and solar power vs. solar voltage (P\&O), Date: 26/12/2013, Time: $2: 45$

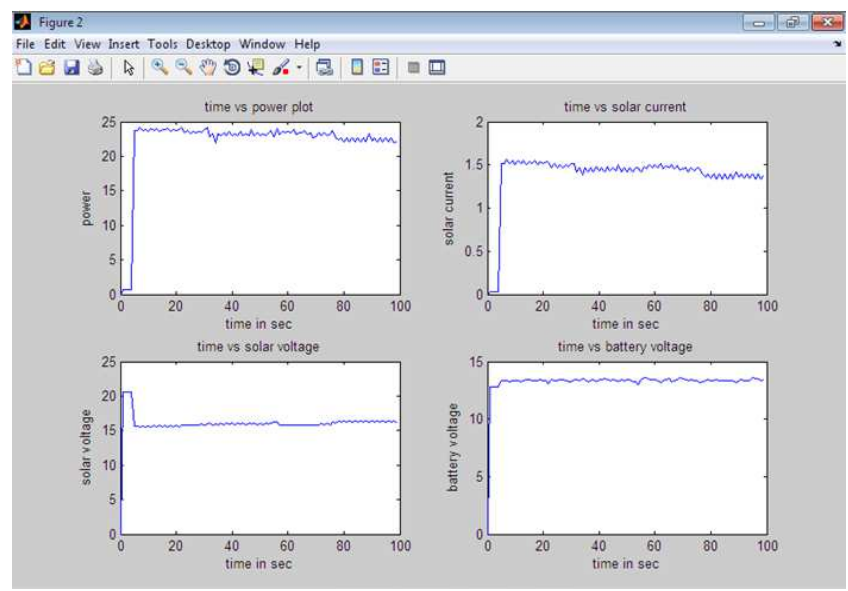

Fig -12: Graph of solar power, current, voltage and battery voltage with respect to time (INC),

Date: 26/12/2013, Time: 2:55

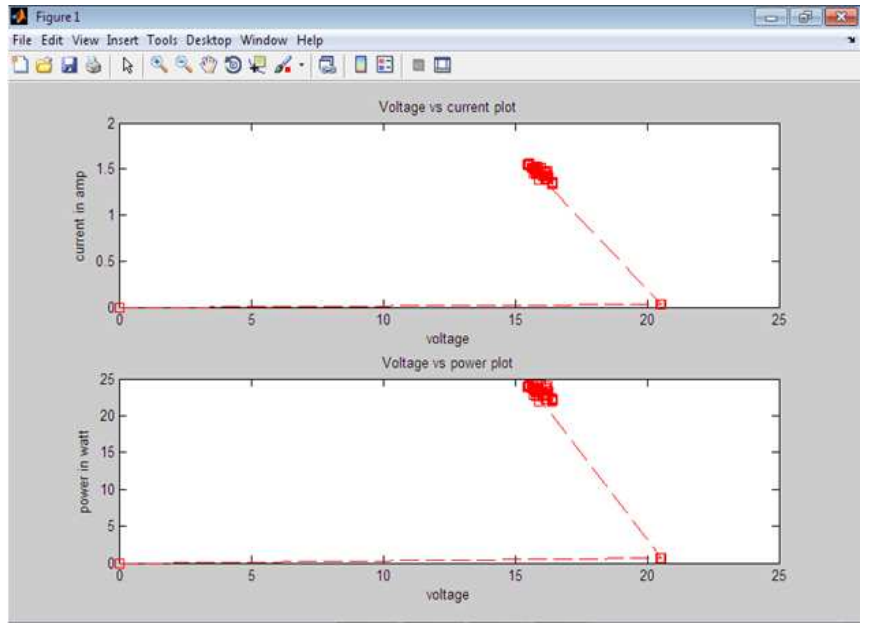

Fig -13: Graph of solar current vs. solar voltage and solar power vs. solar voltage (INC), Date: 26/12/2013,

Time: $2: 55$

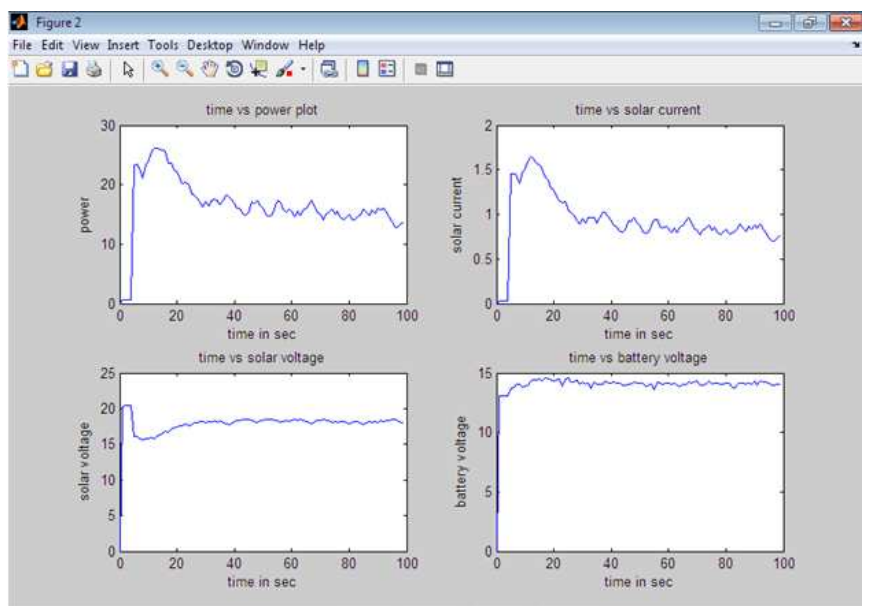

Fig -14: Graph of solar power, current, voltage and battery voltage with respect to time (INC) Date:27/12/2013,Time: 10:32

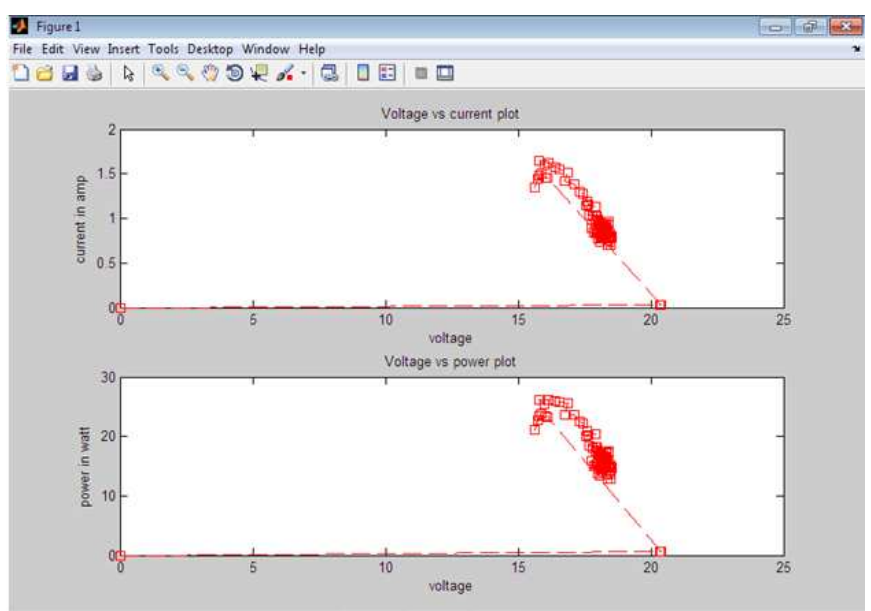

Fig -15: Graph of solar current vs. solar voltage and solar power vs. solar voltage (INC) Date: $27 / 12 / 2013$, Time: 10:32 


\section{BOMBAY}
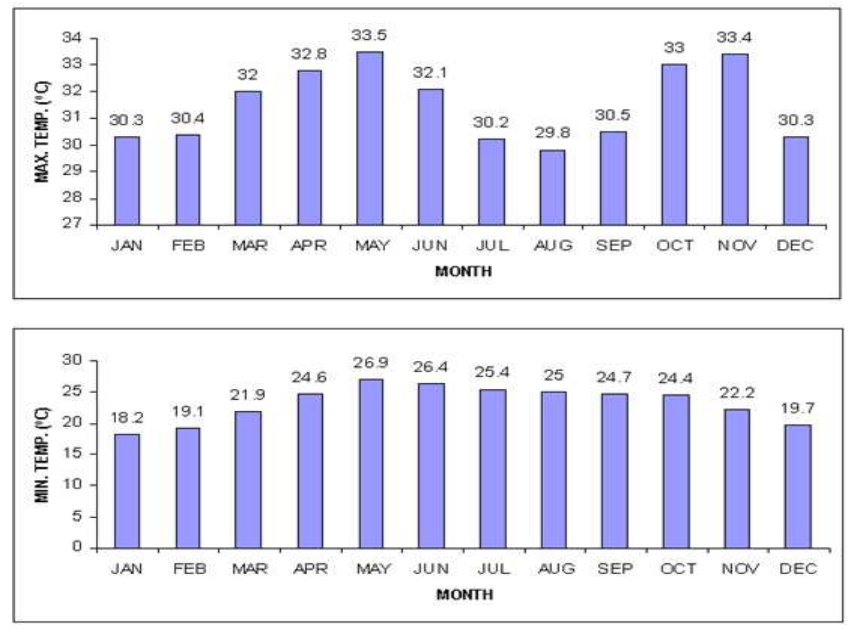

Fig -16: Annual report of temperature (2013):

The experimental test was recorded on 26th and 27th December, 2013 in Mumbai, India. Perturb \& observer and Incremental conductance algorithms based MPPT experiments are performed on these days to show the robustness to the varying atmosphere and compare their performances. We take real time reading on Matlab for 100 second and plot graph of I vs. V, P vs. V and also plot graph of $\mathrm{P}, \mathrm{V}, \mathrm{I}, \mathrm{Vb}$ with respect to time.

Results of perturb \& observer method are shown in Fig -10 and Fig -11 in which Fig -10. has graph of solar power, solar voltage, solar current, battery voltage with respect to time from which we got instantaneous value of solar voltage, solar current, solar power with respect to time and in Fig-11 shows the graph of solar current versus solar voltage and solar power versus solar voltage which shows maximum power point generated by the solar panels when the solar charger was running the perturb and observer algorithm in which solar charger charges battery.

Similarly the Results of incremental conductance method are shown in Fig -12 and Fig -13 in which Fig -12 has graph of solar power, solar voltage, solar current, battery voltage with respect to time from which we would get instantaneous value of solar voltage, solar current, solar power with respect to time and in Fig -13 shows the graph of solar current versus solar voltage and solar power versus solar voltage which shows maximum power point generated by the solar panels when the solar charger was running the incremental conductance algorithm in which solar charger charges battery.

Fig -10 and Fig -13 represents graphs of maximum power point tracker when battery is in bulk condition so it tracks the maximum power point algorithm. Fig -14 and Fig -15 represents graphs of maximum power point tracker when battery is in float condition. In this state we try and keep the battery voltage at 14 volt by decreasing the pwm value.

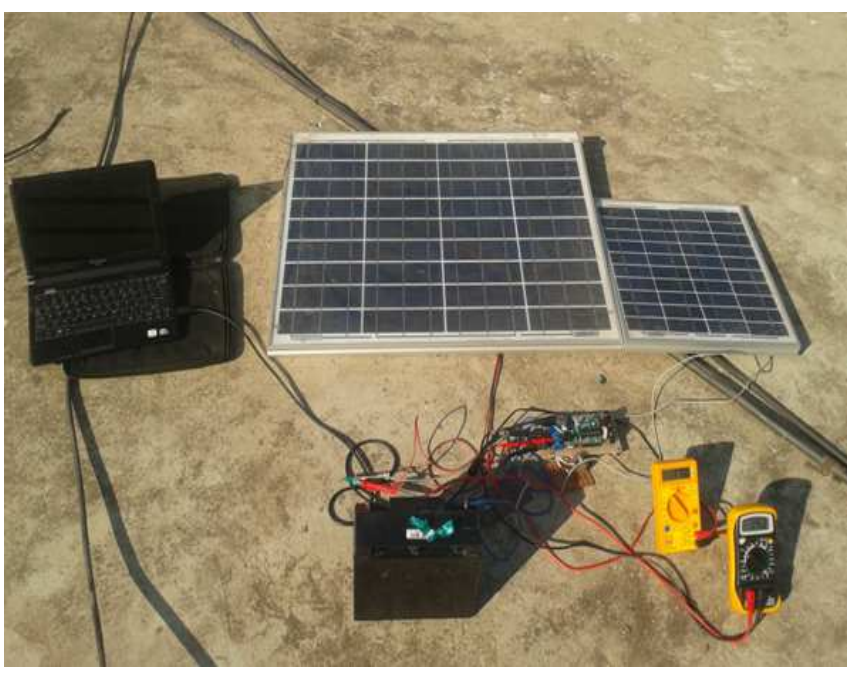

Fig -17: Complete installation of MPPT tracker

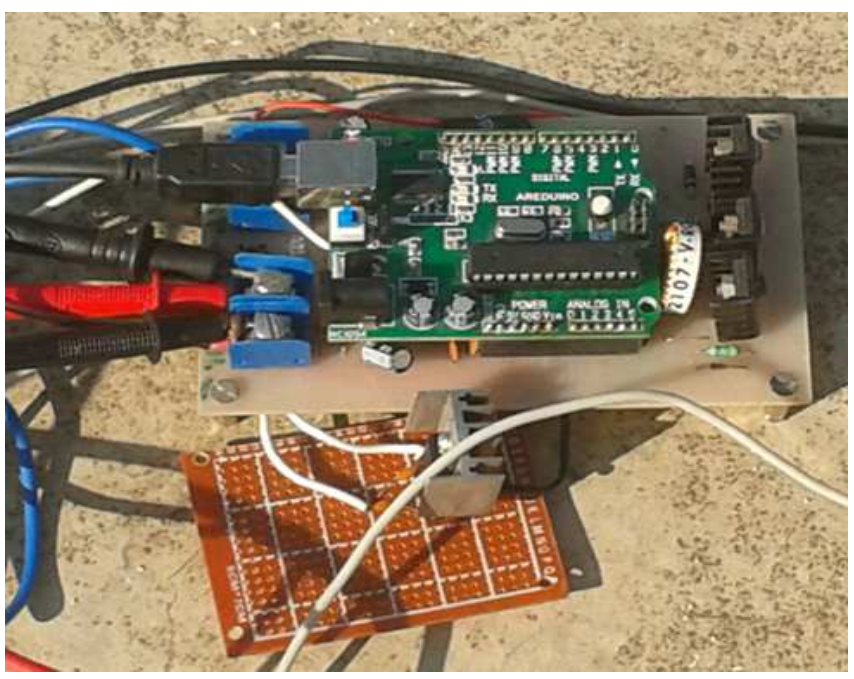

Fig -18: MPPT tracker.

\section{CONCLUSIONS}

Using MPPT with solar panel installations has clear advantages. The initial investment is smaller because smaller panel wattage is required (very little potential power is wasted), and adding correct battery-charging algorithms will also decrease operating costs (batteries are protected and last longer).

In this project we presents two MPPT algorithms implemented on a synchronous Buck converter and compare them on real time graph obtain in Matlab. From this we come to know that Incremental conductance method has less oscillation compare to perturb and observer method which result in higher efficiency.

The maximum power point tracker works because there is a difference between the solar panel's MPP voltage and the 
battery's charging voltage. The IV curves for an actual solar panel show that the MPP voltage goes down as the temperature of the solar panel goes up, this means that the solar panels Maximum power point voltage is lower as the panel temperature rises. On the other hand, if the temperature of the solar panel is low and the battery is mostly discharged, the maximum power point tracker will show higher power gains. My experience with maximum Power point Tracking has shown that large power gains are possible only under ideal circumstances. If the solar panels are cool, the batteries mostly discharged and voltage drops in the system are low, maximum power point tracker gets higher efficiency should occur. Under other conditions the maximum power point tracker efficiency will be lower, especially if the solar panels are being used in hot conditions In this project we presents two MPPT algorithms implemented on a synchronous Buck converter and compare them on real time graph obtain in Matlab. From this we come to know that Incremental conductance method has less oscillation compare to perturb and observer method which result in higher efficiency.

\section{REFERENCES}

[1] W. Xiao, W. G. Dunford, "A modified adaptive hill climbing MPPT method for photovoltaic power systems," in Proc. IEEE PESC, 2004, pp. 1957-1963.

[2] JAW-KUEN SHIAU, Member, IEEE DER-MING MA Design of a Solar Power Management System for an Experimental UAV I.

[3] Safari A, Mekhilef S, "Simulation and Hardware Implementation of Incremental Conductance MPPT with Direct Control Method Using Cuk Converter", IEEE Trans,March 2010.

[4] Trishan Esram, Patrick L. Chapman, "Comparison of Photovoltaic Array Maximum Power Point Tracking Techniques", IEEE Trans. on Energy Conversion, vol. 22,no. 2, pp.439-449, June 2007.

[5] Tat Luat Nguyen, Kay-Soon Low, "A Global Maximum Power Point Tracking Scheme Employing DIRECT Search Algorithm for Photovoltaic Systems," IEEE Transactions on Industrial Electronics, vol. 57, no. 10, pp. 3456-3467, Oct. 2010.

[6] K.H.Hussein, I.Muta, T.Hoshino and M.osakada "Maximum Power Point Tracking: an Algorithm for Rapidly Chancing Atmospheric Conditions", IEE Proc.Gener. Transm.Distrib., vol. 142, no.1, pp. 59-64, January, 1995.

[7] Texas Instruments, "Synchronous Switch-Mode Battery Charge Controller for Solar Power with Maximum Power Point Tracking," Texas Instruments, July 2010. [Online]. Available

[8] [online] http://www.timnolan.com

[9] Mihnea Rosu-Hamzescu, Sergiu Oprea, "Practical Guide to Implementing Solar Panel MPPT Algorithms," Microchip Technology Inc.

[10] [online]http://arduino.cc/en/Main/arduinoBoardDuemil anove
[11] [online]http://batteryuniversity.com/

[12] [online]IsidorBuchmann:http://batteryuniversity.com/le arn/article/charging_the_lead_acid_battery

[13] [online]http://www.irf.com/productinfo/datasheets/data/ ir2104.pdf

[14] [online]http://www.maximintegrated.com/datasheet/ind ex.mvp/id/1971

[15] Microchip Technology Inc. "Buck Converter Design Example"

[16] Anuradha Kar, Asim Kar "A New Maximum Power Point Tracking Algorithm for PV Modules under Partial Shading and Rapidly Varying Illumination", IEEE Trans, University of Calcutta, Kolkata, India, 2009.

[17]Zhou Yan, Liu Fei, Yin Jinjun, Duan Shanxu, "Study on realizing MPPT by improved incremental conductance method with variable step-size”, ICIEA, IEEE Conference on Industrial Electronics and applications, pp. 547 550, June.

[18]Dr. Nirmal-Kumar Nair,Yen-Jung Mark Tung, Dr. Aiguo Patrick $\mathrm{Hu}$,"Evaluation of Micro Controller Based MaximumPower Point Tracking Methods", Dept. of Electrical andComputer Engineering University of Auckland, New Zeland,2006.

[19]Divya Teja Reddy Challa, Raghavendar,Implementation of Incremental Conductance MPPT with Direct Control Method Using Cuk Converter. International Journal of Modern Engineering Research (IJMER), Vol.2, Issue.6, NovDec. 2012 pp-4491-4496 ISSN: 2249-6645

[20] Solar Power (Book) - T Harko

[21] Harnessing Solar Power (Book) - K Zweibel - 1990

[22] REN21 Renewables 2010 Global Status Report

\section{BIOGRAPHIES}

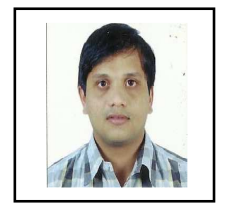

Roshan kini is perusing M.E at Vidyalankar Institute of Technology. He is interested in Power Electronics, Power systems and Renewable energy systems

Prof.Geetha Narayanan has completed her Btech in Electrical and Electronics Engineering from Govt Engineering College Trichur Kerala,India in 1991 and M-Tech in Power Electronics from Regional Engineering College Calicut(NIT Calicut) Kerala ,India in 1994.She is currently working as Associate Professor in Electronics Engonerring at Vidyalankar Institute of Technology 


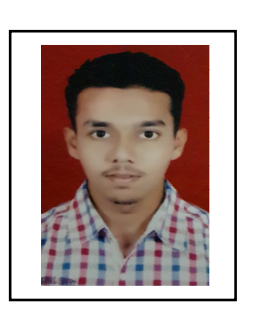

Aditya S. Dalvi, Department of Information Technology,

Mumbai University, Mumbai,

Maharashtra, India.

adityad504@gmail.com 